\title{
Revisión de los modelos hidrogeoquímicos de génesis de tobas calcáreas
}

\section{Hydrochemical models of calcareous tuffs: A review}

\author{
S. Ordóñez ${ }^{1,2}$, D. Benavente ${ }^{1,2}$ \\ 1 Departamento de Ciencias de la Tierra y del Medio Ambiente, Universidad de Alicante, Ap. 99.03080 Alicante, Spain. \\ Email: salvador@ua.es; david.benavente@ua.es \\ 2 Laboratorio de Petrología Aplicada, Unidad Asociada UA-CSIC, Universidad de Alicante
}

\section{RESUMEN}

Los depósitos tobáceos en aguas dulces están ampliamente representados en la Península Ibérica, la mayoría de ellos relacionados con surgencias de acuíferos carbonáticos. Una gran parte de los modelos geoquímicos de la hidroquímica de las aguas en las que se generan dichos depósitos, se basan en suponer que el agua meteórica, previamente enriquecida en $\mathrm{CO}_{2}$ por la existencia de actividad microbiológica en el suelo, fluye a través de la porosidad y de las fracturas de un acuífero de calizo. El agua resultante tiene una naturaleza bicarbonatada cálcica. El reequilibrio con la $\mathrm{pCO}_{2}$ atmosférica después de la surgencia, por agitación del agua, o por acción metabólica de microorganismos fotosintéticos, da lugar a una amplia variedad de facies de tobas calcáreas. Sin embargo, la modelización hidrogeoquímica no ha sido completamente tratada y las condiciones geológicas del entorno no han sido consideradas en sistemas tobáceos generados en zonas de infiltración, en los que el suelo presenta bajas concentraciones de $\mathrm{CO}_{2}$ o cuando la naturaleza de las aguas no son bicarbonatadas cálcicas, sino Ca- $\mathrm{Mg}-\mathrm{SO}_{4}-\mathrm{HCO}_{3}$.

En este trabajo se muestran resultados hidrogeoquímicos de dos ejemplos muy importantes de sistemas tobáceos, actuales y fósiles: río Júcar (Valdeganga- Presa de la Central Hidroeléctrica del Bosque) y río Guadiana Alto (lagunas de Ruidera). Dichos resultados son comparados con otras surgencias kársticas estudiadas recientemente en áreas próximas. La naturaleza del agua del río Júcar y lagunas de Ruidera muestra unas facies hidroquímicas Ca-Mg- $\mathrm{SO}_{4}-\mathrm{HCO}_{3}$. Por lo tanto, la interpretación hidrogeoquímica no puede hacerse usando exclusivamente el sistema $\mathrm{CO}_{2}-\mathrm{H}_{2} \mathrm{O}-$ calcita, el cual por otra parte, ha sido utilizado eficazmente en estudios de tasas de precipitación en sistemas tobáceos, así como en la interpretación del registro paleoclimático de la tobas calcáreas, o en reacciones de karstificación de acuíferos calizos.

En esta revisión evaluamos la influencia en la hidroquímica de las aguas de las reacciones de dedolomitización y la disolución del yeso en acuíferos dolomítico - yesíferos, las cuales son independientes de la presión parcial de $\mathrm{CO}_{2}$, así como la cinética y sostenibilidad del proceso en términos de génesis de sistemas tobáceos. También consideramos otras reacciones dependientes de $\mathrm{CO}_{2}$, tales como la calcificación del yeso y la disolución y precipitación de calcita por mezcla de aguas. Los modelos apuntados explican la naturaleza de las aguas de los acuíferos dolomítico - yesíferos, además de su gran potencial para generar sistemas tobáceos, poniendo en cuestión el argumento de suelos con horizontes húmicos bien desarrollados, no muy comunes en áreas áridas o semi-áridas. Finalmente, examinamos los efectos sobre el grado de saturación calcita y, por lo tanto, de su influencia en la formación de tobas de la mezcla de aguas procedente de acuíferos multicapa o compartimentados temporalmente.

Palabras clave: toba calcárea; aguas dulces carbonatadas; sedimentología; dedolomitización; cinética de disolución; calcita; yeso; dolomita; dióxido de carbono; mezcla de aguas

Recibido el 24 de abril de 2014 / Aceptado el 9 de septiembre de 2014 / Publicado el 16 de octubre de 2014

Citation / Cómo citar este artículo: S. Ordóñez \& D. Benavente (2014). Revisión de los modelos hidrogeoquímicos de génesis de tobas calcáreas. Estudios Geológicos 70(2): e013. http://dx.doi.org/10.3989/egeol.41753.325.

Copyright: () 2014 CSIC. This is an open-access article distributed under the terms of the Creative Commons Attribution-Non Commercial (by-nc) Spain 3.0 License. 


\section{ABSTRACT}

The calcareous tufa deposits in fresh waters are widely represented in the Iberian Peninsula, mostly related to springs from carbonate aquifers. Most studies on the geochemical modelling of the genesis of calcareous tufa consider the meteoric water percolating through the limestone aquifer is enriched in $\mathrm{CO}_{2}$ by existing microbiological activity in soil. The new equilibrium with atmospheric $\mathrm{CO}_{2}$ in springs and/or metabolic activity of microorganisms determines a rich variety of facies of calcareous tufa. The resulting water has a calcium bicarbonate nature. However, the hydrochemical modelling has not completely been addressed and the boundary conditions have not been taken into account in tufa systems in which soils present low $\mathrm{CO}_{2}$ concentrations or when the nature of waters are $\mathrm{Ca}-\mathrm{Mg}-\mathrm{SO}_{4}-\mathrm{HCO}_{3}$.

In this paper, hydrochemical results from two important examples of genesis of calcareous tufa are presented: Júcar river (Valdeganga - Presa de la Central Hidroeléctrica del Bosque) and Guadiana Alto river (Ruidera pools). These results are also compared with other kart spring waters recently studied in the area. The water nature of Júcar river and Ruidera aquifers shows clearly a Ca-Mg- $\mathrm{SO}_{4}-\mathrm{HCO}_{3}$ facies. The hydrochemical interpretation cannot exclusively be explained using the $\mathrm{CO}_{2}-\mathrm{H}_{2} \mathrm{O}$ - calcite system, which has widely been used in studies of precipitation rates and paleoclimatic records of calcareous tufa or Karstification reactions of limestone aquifers. In this review, we evaluate the dedolomitization and gypsum dissolution, which are independent of partial pressure of $\mathrm{CO}_{2}$, and kinetics and sustainability of processes in terms of genesis of tufa systems. We also consider other $\mathrm{CO}_{2}$-dependent reactions such as the calcification gypsum and dissolution and precipitation of calcite by mixing waters. This explains the nature of waters from dolomite-gypsum aquifers and also their great generator potential of tufa systems, and refuses the interpretation based exclusively on the presence of humic acid-rich soils, not very common in arid and semi-arid areas. Finally, we examine mixing waters in multi-layered or compartmentalized seasonally aquifers, which can produce waters that develop calcareous tufa.

Keywords: calcareous tufa; fresh water carbonates; sedimentology; dedolomitization; kinetics of dissolution; calcite; gypsum; dolomite; carbon dioxide; mixing waters

\section{Introducción}

\section{Las tobas calcáreas - aguas meteógenas}

Las tobas calcáreas, o tobas de agua dulce, presentan un gran interés científico, que deriva de su amplia distribución en los medios continentales a lo largo de los tiempos geológicos, y además porque estos materiales constituyen un importante registro de información paleoambiental y paleoecológica (Capezzuoli et al., 2013). En general, el modelo conceptual de la génesis de tobas calcáreas y la información de las señales paleoclimáticas y paleoambientales que contienen se basa en la observación y comúnmente se acepta que las variaciones del sistema $\mathrm{CO}_{2}-\mathrm{H}_{2} \mathrm{O}$-rocas carbonáticas son la base del proceso de disolución - precipitación de calcita.

$\mathrm{El} \mathrm{CO} 2$ tiene un origen muy diverso y se considera fundamentalmente atmosférico y edáfico, no considerándose el generado por la oxidación de la materia orgánica dispersa en los sedimentos. En general, se considera que el agua meteórica se infiltra a través de acuíferos carbonáticos, más o menos karstificados. Su posterior surgencia en fuentes, manantiales o infiltraciones en los puntos de intersección del nivel freático con la superficie topográfica constituyen los ambientes sedimentarios más aceptados para la génesis de tobas calcáreas.

Las aguas meteóricas, aguas meteógenas en la nomenclatura de Pentecost \& Viles (1994) y Pentecost (2005), tienen una hidroquímica específica y común en manantiales de terrenos kársticos. El mecanismo genético generalmente aceptado implica que el agua de lluvia se ha filtrado a través de un horizonte edáfico, en el que la presión parcial de $\mathrm{CO}_{2}, p \mathrm{CO}_{2}$, puede aumentar hasta más de 10 veces la correspondiente a áreas rurales. Dicho aumento de la $\mathrm{pCO}_{2}$ juega un importante papel de movilización de los carbonatos, saturando las aguas en iones calcio y bicarbonato.

La modelización de estos procesos se encuentra ampliamente recogida en la bibliografía. De acuerdo con Glynn \& Plummer (2005) se pueden distinguir básicamente dos modos de abordar la modelización de la hidroquímica de las aguas subterráneas e interpretar su comportamiento: modelización directa e indirecta. La modelización directa se basa en simular el resultado de un conjunto de reacciones y condiciones iniciales usando diferentes modelos de cálculo de coeficientes de actividad y bases de datos termodinámicas, tanto para reacciones acuosas de especiación 
homogéneas como de transferencia de masa entre fases. Así, la modelización hidrogeoquímica directa de las aguas se ha usado frecuentemente en la interpretación de los datos hidrogeoquímicos de las aguas de las surgencias, intentando comprender las reacciones del sistema suelo-agua, y poniendo en valor la influencia de la $\mathrm{pCO}_{2}$ como un factor petrogenético básico, tanto en la movilización como en la precipitación de carbonatos. La modelización geoquímica inversa (utilizada inicialmente por Garrels \& Mackenzie, 1967) aplica un balance de masas a una composición química e isotópica de un agua analizada, estimando la masa de mineral y gas que se transfieren en los sistemas agua-roca. Una combinación de la modelación inversa, junto con los criterios de flujo y transporte de masa, puede proporcionar una mejora del conocimiento y de la comprensión de la hidroquímica de las aguas subterráneas, y ayudar a la interpretación y la modelización directa de los procesos de precipitación de fases minerales en las surgencias. Por lo tanto resulta de aplicación a la génesis de tobas calcáreas generadas a partir de acuíferos con aguas carbonatadas desde débilmente sulfatadas hasta muy sulfatadas.

Recientemente, Brasier (2011) revisó estos modelos aplicándolos a aplicandolosy bicarbonaton: la génesis de espeleotemas, carbonatos edáficos y tobas - travertinos poniendo de manifiesto la complejidad de esta modelización. La simplicidad del sistema $\mathrm{CO}_{2}-\mathrm{H}_{2} \mathrm{O}$ - rocas carbonáticas (calcíticas, dolomíticas y/o yesíferas) se les añade la presencia en los sistemas naturales de otros tipos petrológicos y la variación de la temperatura del agua de infiltración.

El objetivo de la presente revisión es examinar la influencia de los aspectos anteriormente expuestos y discutir otros que no suelen abordarse usualmente en la modelización hidrogeoquímica de génesis de tobas calcáreas y, sin embargo, consideramos son imprescindibles: a) la cinética diferencial de disolución - precipitación y su relación con el tiempo de permanencia del agua en el acuífero; b) el carácter limitante de la sostenibilidad de algunas de estas reacciones, ya que la necrosis de la porosidad consecuencia del balance de volúmenes molares en los procesos de disolución incongruente, puede bloquear la circulación de aguas por el acuífero; c) la importancia que en acuíferos multicapa y compartimentados puede tener la mezcla de aguas ya que modifican el índice de saturación de las fases minerales y en especial, el de la calcita en el agua de mezcla. Este proceso puede producirse a lo largo de los valles donde se generan las tobas calcáreas a partir de la mezcla del agua surgente con las aguas que circulan o están en las lagunas.

\section{Modelos basados en la variación de la $\mathrm{pCO}_{2}$ a lo largo del ciclo hidrológico}

Thraikill (1968) señala la importancia del $\mathrm{CO}_{2}$ en el desarrollo de cavidades kársticas en base al estudio físico-químico de la variación de la $\mathrm{pCO}_{2}$, desde los procesos de precipitación; infiltración en el suelo, con un aumento sustancial de la $\mathrm{pCO}_{2}$; y posterior surgencia en una cavidad o en la superficie topográfica. Como primera aproximación a los modelos en los que la variación de la $\mathrm{pCO}_{2}$, a lo largo del ciclo hidrogeológico los procesos de precipitación - infiltración - surgencia se consideran el mecanismo fundamental de transferencia de masa del acuífero a la génesis de formaciones tobáceas. En la fig. 1 se establece el modelo conceptual básico para los carbonatos continentales, que está basado en el esquema conceptual de Ordóñez \& García del Cura (1982) y validado por Pedley et al., (2009) y Banks \& Jones (2012).

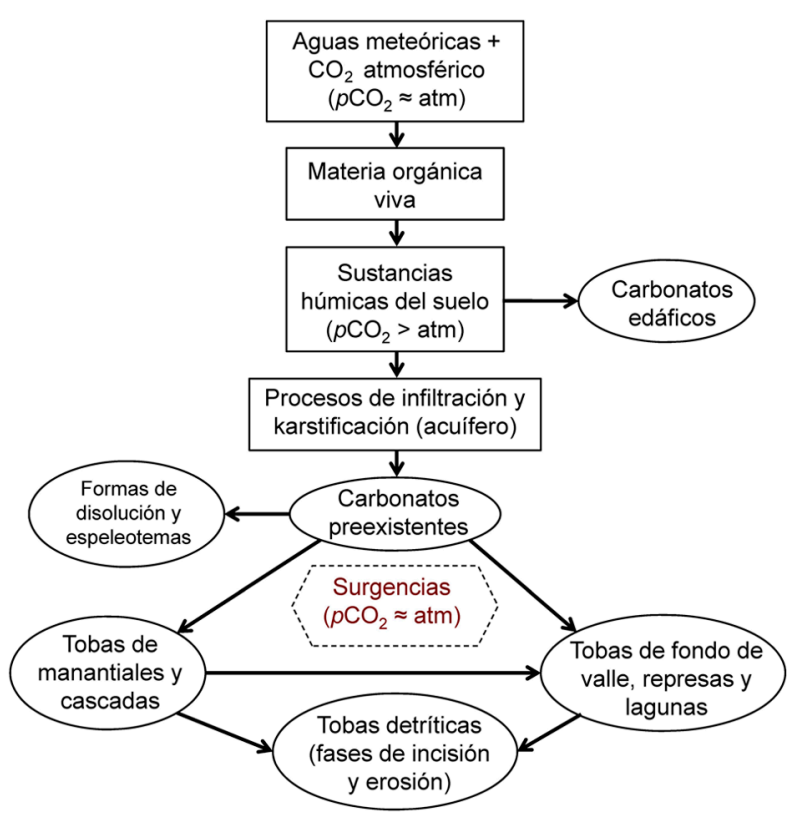

Fig. 1.-Esquema general de génesis de tobas y otros carbonatos de aguas dulce (modificado de Ordóñez \& García del Cura, 1982). 
En la fig. 2, se muestra el diagrama de equilibrio $\mathrm{CO}_{2}-\mathrm{H}_{2} \mathrm{O}$ - calcita - dolomita, expresado como función de la $\log p \mathrm{CO}_{2}$ y del $\log \mathrm{aCa}{ }^{2+}$. Dicho modelo se apoya parcialmente el modelo de la fig. 1 y se ha usado en el diseño de modelo de génesis de tobas calcáreas de Ordóñez \& Felipe (1988), en el que se parte del equilibrio politermal $\mathrm{CO}_{2}-\mathrm{H}_{2} \mathrm{O}$ - calcita - dolomita - yeso. Las líneas verticales de puntos del diagrama representan respectivamente, el $\log p \mathrm{CO}_{2}=-3.5$ típica de una atmosfera rural, no contaminada; y la línea de $\log p \mathrm{CO}_{2}=-1.5$, correspondiente a suelos con intensos procesos microbiológicos de putrefacción, en horizontes edáficos ricos en materia orgánica.

Estas aguas de infiltración enriquecida en $\mathrm{CO}_{2}$ actúan sobre los materiales carbonatados de acuífero, produciendo amplios procesos de disolución, dependiendo del tiempo de residencia y de la temperatura del agua. Cuando las aguas del acuífero surgen en fuentes y manantiales, se reequilibra con la presión atmosférica y se produce la sobresaturación en calcita de las aguas. El mecanismo de desgasificación y reequilibrio pueden ser muy variado. La desgasificación por turbulencia está fuertemente relacionada con el régimen del flujo de agua, que es función de las características geométricas y de pendiente del canal de desagüe. Por otro lado se encuentra la actuación de organismos secuestradores de $\mathrm{CO}_{2}$, con actividad fotosintética (cianofíceas) que se fijan sobre el sustrato o sobre plantas superiores (epifitas), danto texturas características que se han interpretado en relación con biofilms (Ordóñez et al., 1978; Souza-Egipsy et al., 2006; Rogerson et al., 2008; Pedley et al., 2009). Recientemente, los experimentos de Pedley (2014) confirman el carácter biogeoquímico de los procesos de precipitación de los carbonatos por difusión de iones de calcio a través de procesos de quelación en el seno de las sustancias poliméricas extracelulares (EPS, del inglés extracellular polymeric substances), que quedan mineralizadas en los depósitos y han sido profusamente descritos en la bibliografía.

\section{Hidroquímica de las Lagunas de Ruidera y del valle del Río Júcar (Villargordo - Central H. del Bosque)}

Para poder establecer la validez de los modelos genéticos basados en la variación de la presión de parcial de $\mathrm{CO}_{2}, p \mathrm{CO}_{2}$, vamos a establecer

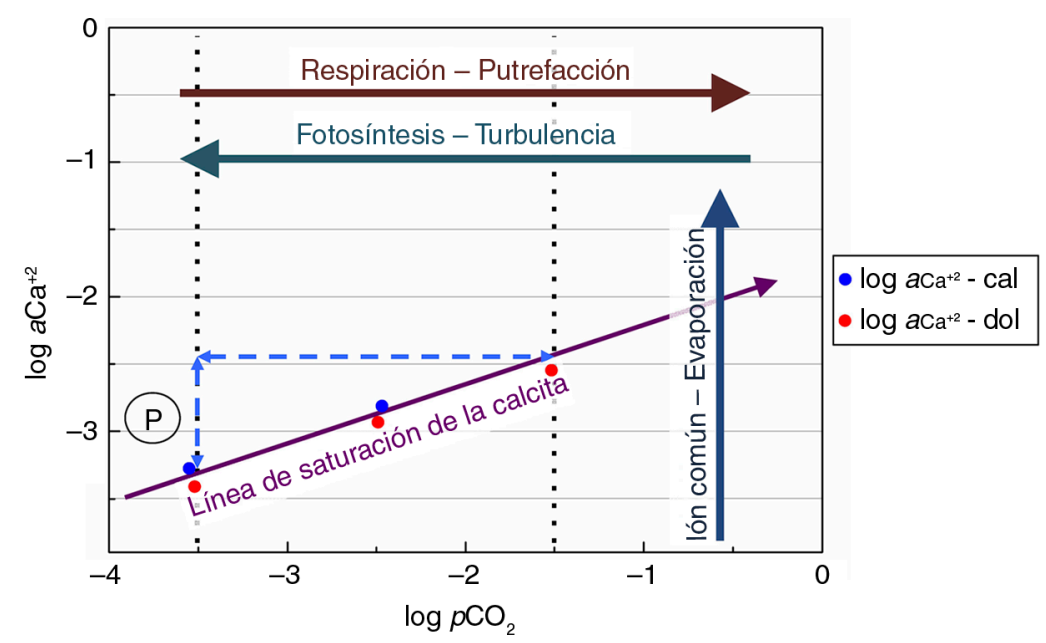

Fig. 2.-Diagrama de equilibrio para la calcita/dolomita en función de la log $p \mathrm{CO}_{2}-\log \mathrm{aCa}^{2+}$. En el mismo se han situado unas líneas verticales de puntos, representan respectivamente: a) $\log p \mathrm{CO}_{2}=-3.5$, correspondiente a una atmosfera rural; y b) $\log p \mathrm{CO}_{2}=-1.5$, correspondiente a suelos ricos en materia orgánica, con intensos procesos microbiológicos de putrefacción. Los procesos que tiene lugar en la zona de infiltración del acuífero vienen definidos por la "Respiración (oxidación) - Putrefacción". Cuando las aguas del acuífero surgen en fuentes y manantiales, su $\mathrm{pCO}_{2}$ se reequilibra con la presión de $\mathrm{CO}_{2}$ ambiental por efecto de la "Fotosíntesis y/o Turbulencia" $\mathrm{y}$, como consecuencia, el agua se sobresatura en calcita. El salto definido por la diferencia de aCa ${ }^{2+}, \mathrm{P}_{\text {, nos permite }}$ valorar la capacidad de precipitar tobas por parte del agua de la surgencia, función de la diferencia de la presión de $\mathrm{pCO}_{2}$ del acuífero y la atmosférica, el cambio térmico de las aguas y la influencia de la Fotosíntesis-Turbulencia. También influye en la capacidad de precipitar tobas la simple evaporación y el efecto de ion común (calcio procedente de la disolución de otros minerales). Este efecto de ion común será analizado más en detalle en el trabajo. 
la comparación entre dos sistemas de tobas bien conocidos: Ruidera y valle del Río Júcar (Valdeganga - Central Hidroeléctrica de Bosque). Se trata de sistemas hídricos que se encuentran en climas parecidos, pero con amplias diferencias en las características del acuífero, tiempo de permanencia y régimen de descarga. En ambos casos se han formado a lo largo de los valles importantes depósitos de tobas calcáreas de barrera, activas en la actualidad, y abundantes en el registro fósil. Dichos ejemplos reúnen datos hidrogeológicos e hidroquímicos, fruto de la importancia económica y necesidad de regular la extracción del agua para usos agrarios. Por último en este apartado hemos incluido una comparación con los datos e interpretación hidroquímica del acuífero de la Sierra del Segura.

\section{Las Lagunas de Ruidera}

Las Lagunas de Ruidera representan sin duda uno de los sistemas de represas tobáceas mejor conocidos de la península Ibérica. En ellas se han identificado, y datado usando edades U-Th, cuatro episodios de desarrollo de tobas, 190-250 ka AP, 90-130 ka A.P., 30-40 ka A.P. y 16 ka A.P, continuando el proceso en la actualidad, alternando, con amplios periodos de destrucción de edificios tobáceos que han rellenado de tobas detríticas el valle del Rio Guadiana, aguas arriba de la presa de Peñarroya (Ordóñez et al., 2005). Las lagunas situadas tras las represas tobáceas presentan una abundante sedimentación de carbonatos lacustres, así como amplias repisas tobáceas con fábricas estromatolíticas.

Las Lagunas de Ruidera han sido objeto de muchos estudios tanto desde el punto de vista hidrogeológico (Niñerola \& Torrens, 1979; Montero, 1994; Eugercios, 2013), como hidroquímico (Eugercios, 2013). Eugercios (2013) señala la importancia de los procesos de dedolomitización y del efecto de ion común (yeso) sobre la hidroquímica de la aguas del acuífero de Ruidera.

El acuífero principal que alimenta este sistema fluvial de las Lagunas de Ruidera está formado por dolomías y calizas del Lías inferior, con una elevada permeabilidad por conexión de poros y fisuración, con porosidades que oscilan entre 15-20\%. La capacidad de almacenamiento se ha calculado en $2835 \mathrm{hm}^{3}$, siendo el tiempo de renovación medio del agua de 28 años (Eugercios, 2013). Dicho acuífero se puede considerar como unicapa, no confinado y muy compartimentado, en etapas de estiaje. El espesor de esta unidad oscila entre 75-100 m. Su transmisividad varía 50-1500 m²/día (Niñerola \& Torrens, 1979) y es muy alta en la zona próxima a las Lagunas de Ruidera. Estos materiales dolomíticos, con amplios procesos de carniolización, se disponen sobre las margas y arcillas yesíferas de las facies Keuper. Las calizas oolíticas del Lías superior que afloran en la zona oriental también constituyen un acuífero, si bien su permeabilidad y su importancia es bastante menor. Las calizas y brechas calcáreas del Terciario superior también forman pequeños acuíferos colgados.

La única fuente de recarga del acuífero es la precipitación debido a que no existen aportes procedentes de otras cuencas hidrográficas. Las precipitaciones se infiltran en el sustrato de elevada permeabilidad del Lías por lo que existe una notable ausencia de cauces superficiales, salvo los relacionados con los manantiales y surgencias del acuífero. Los cauces fluviales sólo funcionan excepcionalmente a pocos días de grandes precipitaciones, en las que se supera la capacidad de almacenaje del acuífero.

Las Lagunas de Ruidera sufrieron en el periodo posterior a 1986 las consecuencias de una gran sequía y sobreexplotación de acuíferos, secándose algunas, e incluso dejaron de verter agua al Embalse de Peñarroya. A finales de 1995 comienza una etapa de intensas precipitaciones, lo que permite el llenado de las lagunas de forma descendente, desde las situadas en la parte alta del valle (Grande et al., 1997). Tras meses de lluvias se recuperó el nivel del acuífero y en unos pocos días empieza a producirse rebases de represas e incluso "sifonamientos" de las represas tobáceas, proceso que provoca su erosión parcial y puntual. Este proceso, junto con otros condicionantes geomorfológicos, explican la génesis de tobas detríticas tan comunes a lo largo del sistema tobáceo de las Lagunas de Ruidera, descritas en Ordóñez et al., (2005).

Desde el punto de vista hidrogeológico, todo ello indica que una vez restablecido el nivel freático, los excedentes de agua manaban a lo largo y en sentido descendente del valle y, en un corto periodo de tiempo (par de meses), se restablecía el equilibrio infiltración - descarga; aspecto que sin duda se relaciona con la alta transmisividad del acuífero. 
Las descargas se localizan en el contacto entre el acuífero calcítico - dolomítico y el acuitardo, definido por materiales arcillosos - yesíferos - con eflorescencias de cloruros (facies Keuper). También se puede producir allí donde la superficie topográfica corta al nivel freático, como ocurre en el fondo de las lagunas, produciéndose procesos de infiltración y descarga a lo largo del valle. Las facies Keuper afloran en forma de umbrales, lo cual compartimenta el acuífero y condiciona el flujo de agua subterránea, generando procesos de mezcla de aguas en puntos determinados.

En la fig. 3, se representan en un diagrama de Piper los datos de las aguas del sistema hidrogeológico de Ruidera, tomados y reinterpretados de Plata \& Pérez-Zabaleta (1995). Dichas aguas se dividen por su ubicación en aguas de piezómetros (pertenecen al acuífero, y son las menos reequilibradas con la $\mathrm{pCO}_{2}$ atmosférica), surgencias y manantiales (son aguas cuya $\mathrm{pCO}_{2}$ está reequilibrándose y las lagunas representan cuerpos de agua permanentes, sometidos a desgasificación biológica (planctónica y bentónica) y a variaciones térmicas). Las aguas de los piezómetros reflejan la composición química del agua del acuífero, fuera del contacto con la atmósfera. En las aguas de las surgencias y manantiales existe ya un inicio de reequilibrio con la $\mathrm{pCO}_{2}$ atmosférica. Por otro lado, las aguas de las lagunas están sometidas a la acción del desarrollo de macroflora bentónica, sobre la que se desarrolla una importante comunidad de cianobacterias epifitas y algas diatomeas que modelan represas y repisas, sin olvidar la precipitación de carbonatos lacustres y terrígenos.

Las aguas muestreadas pueden clasificarse como sulfatadas - cálcicas - magnésicas a aguas bicarbonatadas - cálcicas - magnésicas, con un contenido apreciable en iones cloruro y sodio. Los índices de saturación, calculados con el PHREEQC (Parkhurst \& Appelo, 1999) a $25^{\circ} \mathrm{C}$, de la calcita, dolomita y yeso se recogen en la Tabla 1. El yeso se encuentra subsaturado en los tres tipos de aguas, mientras que la calcita y la dolomita se encuentran ligeramente sobresaturadas en lagunas y piezómetros, mientras que en los manantiales se encuentran saturadas (equilibrio) en calcita y subsaturadas en dolomita.

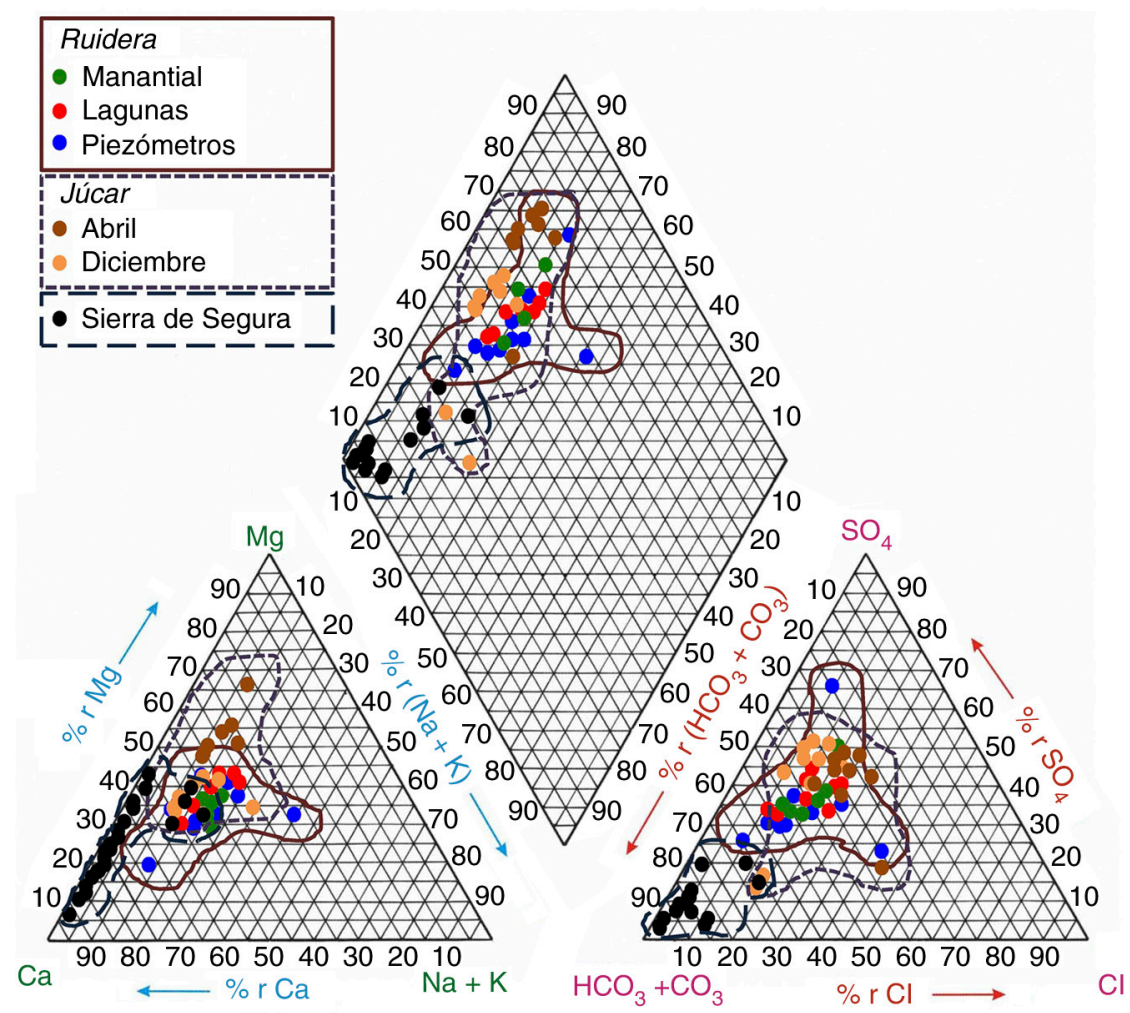

Fig. 3.-Diagrama de Piper de los sistemas de las Lagunas de Ruidera, Río Júcar y de la Sierra de Segura (recogidos en Moral et al., 2008). 


\begin{tabular}{|c|c|c|c|c|c|c|c|c|c|c|c|c|c|c|}
\hline & $\begin{array}{c}\mathrm{Cl}^{-} \\
{[\mathrm{ppm}]}\end{array}$ & $\begin{array}{c}\mathrm{SO}_{4}^{2-} \\
{[\mathrm{ppm}]}\end{array}$ & $\begin{array}{l}\mathrm{HCO}_{3}^{-} \\
{[\mathrm{ppm}]}\end{array}$ & $\begin{array}{c}\mathrm{NO}_{3}^{-} \\
{[\mathrm{ppm}]}\end{array}$ & $\begin{array}{c}\mathrm{Na}^{+} \\
{[\mathrm{ppm}]}\end{array}$ & $\begin{array}{c}\mathrm{Mg}^{+2} \\
{[\mathrm{ppm}]}\end{array}$ & $\begin{array}{c}\mathrm{Ca}^{+2} \\
{[\mathrm{ppm}]}\end{array}$ & $\begin{array}{c}\mathrm{K}^{+} \\
{[\mathrm{ppm}]}\end{array}$ & $\mathrm{pH}$ & $\begin{array}{c}\sigma \\
{[\mu \mathrm{s} / \mathrm{cm}]}\end{array}$ & $\mathrm{IS}_{\text {calcita }}$ & $I_{\text {dolomita }}$ & $\mathrm{IS}_{\text {yeso }}$ & $\begin{array}{c}\log \\
\mathrm{pCO}_{2}\end{array}$ \\
\hline \multicolumn{15}{|c|}{ Lagunas } \\
\hline Min & 35.40 & 85.60 & 103.70 & 13.00 & 20.00 & 19.40 & 48.00 & 1.40 & 7.30 & 543.00 & -0.52 & -1.10 & -1.76 & -2.89 \\
\hline Max & 63.70 & 109.60 & 213.50 & 47.10 & 27.60 & 31.60 & 76.00 & 2.60 & 8.10 & 635.00 & 0.62 & 1.08 & -1.63 & -2.25 \\
\hline Media & 48.80 & 94.85 & 156.11 & 26.19 & 24.05 & 25.21 & 63.65 & 2.19 & 7.66 & 596.36 & 0.03 & -0.09 & -1.68 & -2.55 \\
\hline SD & 8.96 & 7.91 & 35.11 & 11.23 & 2.44 & 3.59 & 9.70 & 0.35 & 0.23 & 31.19 & 0.35 & 0.66 & 0.04 & 0.20 \\
\hline \multicolumn{15}{|c|}{ Manantiales } \\
\hline Min & 42.50 & 85.60 & 85.40 & 3.70 & 19.00 & 20.60 & 56.00 & 1.20 & 7.30 & 510.00 & -0.55 & -1.30 & -1.73 & -2.84 \\
\hline Max & 56.60 & 110.70 & 186.00 & 47.80 & 29.00 & 25.50 & 74.00 & 2.20 & 7.80 & 764.00 & 0.05 & -0.13 & -1.63 & -2.11 \\
\hline Media & 48.95 & 94.45 & 146.90 & 36.35 & 24.52 & 22.87 & 65.00 & 1.73 & 7.50 & 615.67 & -0.18 & -0.59 & -1.66 & -2.43 \\
\hline SD & 5.20 & 8.62 & 41.38 & 16.76 & 3.43 & 1.79 & 8.07 & 0.45 & 0.20 & 99.76 & 0.21 & 0.44 & 0.04 & 0.27 \\
\hline \multicolumn{15}{|c|}{ Piezómetros } \\
\hline Min & 42.50 & 86.40 & 152.50 & 1.20 & 17.00 & 15.80 & 68.00 & 1.60 & 7.20 & 651.00 & -0.39 & -1.06 & -1.70 & -2.81 \\
\hline $\operatorname{Max}$ & 169.90 & 344.00 & 305.00 & 61.10 & 92.40 & 38.90 & 136.00 & 3.30 & 8.00 & 1015.00 & 0.80 & 0.91 & -0.94 & -1.96 \\
\hline Media & 68.02 & 121.92 & 194.59 & 29.44 & 32.93 & 27.83 & 85.80 & 2.54 & 7.50 & 785.30 & 0.04 & -0.21 & -1.53 & -2.30 \\
\hline SD & 38.90 & 78.90 & 44.40 & 19.59 & 21.72 & 8.17 & 24.03 & 0.49 & 0.30 & 136.06 & 0.38 & 0.71 & 0.22 & 0.29 \\
\hline
\end{tabular}

Las correlaciones (lineales) entre las diferentes especies se muestran en la Tabla 2.

En los tres tipos de aguas, hay agrupaciones que se repiten, como $\mathrm{Na}-\mathrm{Cl}$ (asociado a las facies Keuper), y otras que cambian en los diferentes tipos de aguas. Así, los $\mathrm{SO}_{4}$ y $\mathrm{Ca}$ (que se asocia a la disolución del yeso/ anhidrita), están agrupados en las aguas de las lagunas y piezómetros. La relación entre el $\mathrm{HCO}_{3}, \mathrm{Ca}$ y $\mathrm{pH}$ (disolución -precipitación de calcita) sólo se muestra en las aguas de lagunas y manantiales; en las aguas de piezómetros el $\mathrm{HCO}_{3}$ se asocia al Mg. En las aguas de piezómetros, los $\mathrm{Mg}, \mathrm{Ca}$ y $\mathrm{SO}_{4}$ se agrupan poniendo de manifiesto los procesos de dedolomitización.

La interpretación de la hidroquímica de las aguas, según Eugercios (2013), se relaciona con procesos de disolución de yesos, seguida de la disolución de calcita, y la dedolomitización. La dedolomitización, definida no ortodoxamente, en función de la presencia de yeso:

$$
\begin{aligned}
& 1.8 \mathrm{CaSO}_{4}+0.8 \mathrm{CaMg}\left(\mathrm{CO}_{3}\right)_{2} \rightarrow 1.6 \mathrm{CaCO}_{3} \\
& +\mathrm{Ca}^{2+}+0.8 \mathrm{Mg}^{2+}+1.8 \mathrm{SO}_{4}^{2-}
\end{aligned}
$$

Eugercios (2013) añade al modelo hidroquímico los procesos de desgasificación y de mezcla de aguas. Más adelante se discutirá sobre esta interpretación, pero conviene señalar que esta reacción no está afectada por la $\mathrm{pCO}_{2}$ en las aguas del suelo.
Los depósitos tobáceos del valle del Río Júcar entre Valdeganga - Central Hidroeléctrica del Bosque

En el área entre Valdeganga y la Central Hidroeléctrica del Bosque (Presa de El Molinar) del valle del Río Júcar se han identificado grandes represas y aterrazamientos Pleistocenos, entre 239 ka y 95 ka A.P., formando edificios que se sitúan entre 20-50 m (Fernández-Fernández, 1996; FernándezFernández et al., 1997, 1999, 2000). Así mismo se han identificado depósitos holocenos y funcionales actuales de represas tobáceas con abundantes terrígenos que, en general, se asocian a rápidos del río, condicionados por cambios en la pendiente. Las muestras de agua para el estudio hidroquímico para esta revisión se han tomado precisamente en la zona en que aparecen las formaciones tobáceas, en periodo de primavera e invierno.

El valle del Jucar (Valdeganga - Central Hidroeléctrica del Bosque) se asienta en el sistema acuífero de la Mancha Oriental (Sanz, 2005; Sanz et al., 2005). Está situado en el extremo oriental de la llanura manchega con una extensión de unos $7.600 \mathrm{Km}^{2}$. El sistema hidrogeológico se puede considerar como un acuífero multicapa formado por la superposición de varias unidades acuíferas de naturaleza diversa. La Unidad Hidrogeológica 
Tabla 2.-Matriz de correlación lineal entre la concentración de los elementos mayores y el pH para aguas de las lagunas, manantiales y piezómetros de las laguas de Ruidera

\begin{tabular}{|c|c|c|c|c|c|c|c|c|c|}
\hline & $\mathrm{Cl}^{-}$ & $\mathrm{SO}_{4}^{2-}$ & $\mathrm{HCO}_{3}^{-}$ & $\mathrm{NO}_{3}^{-}$ & $\mathrm{Na}^{+}$ & $\mathrm{Mg}^{+2}$ & $\mathrm{Ca}^{+2}$ & $\mathrm{~K}^{+}$ & $\mathrm{pH}$ \\
\hline \multicolumn{10}{|c|}{ Lagunas } \\
\hline $\mathrm{C}^{-}$ & 1.00 & & & & & & & & \\
\hline $\mathrm{SO}_{4}^{2-}$ & & 1.00 & & & & & & & \\
\hline $\mathrm{HCO}_{3}^{-}$ & & -0.68 & 1.00 & & & & & & \\
\hline $\mathrm{NO}_{3}^{-}$ & -0.52 & & & 1.00 & & & & & \\
\hline $\mathrm{Na}^{+}$ & 0.75 & 0.53 & -0.52 & & 1.00 & & & & \\
\hline $\mathrm{Mg}^{+2}$ & & & & & & 1.00 & & & \\
\hline $\mathrm{Ca}^{+2}$ & & -0.74 & 0.92 & & -0.59 & & 1.00 & & \\
\hline $\mathrm{K}^{+}$ & & & & & & & & 1.00 & \\
\hline $\mathrm{pH}$ & & & 0.60 & -0.56 & & & 0.53 & & 1.00 \\
\hline \multicolumn{10}{|c|}{ Manantiales } \\
\hline $\mathrm{Cl}^{-}$ & 1.00 & & & & & & & & \\
\hline $\mathrm{SO}_{4}^{2-}$ & & 1.00 & & & & & & & \\
\hline $\mathrm{HCO}_{3}^{-}$ & & & 1.00 & & & & & & \\
\hline $\mathrm{NO}_{3}^{-}$ & -0.56 & & & 1.00 & & & & & \\
\hline $\mathrm{Na}^{+}$ & 0.57 & & 0.77 & & 1.00 & & & & \\
\hline $\mathrm{Mg}^{+2}$ & & & & -0.64 & & 1.00 & & & \\
\hline $\mathrm{Ca}^{+2}$ & & & 0.89 & & 0.83 & & 1.00 & & \\
\hline $\mathrm{K}^{+}$ & 0.83 & & 0.55 & -0.72 & 0.73 & & 0.56 & 1.00 & \\
\hline $\mathrm{pH}$ & & & & & -0.74 & & -0.62 & -0.58 & 1.00 \\
\hline \multicolumn{10}{|c|}{ Piezómetros } \\
\hline $\mathrm{Cl}^{-}$ & 1.00 & & & & & & & & \\
\hline $\mathrm{SO}_{4}^{2-}$ & & 1.00 & & & & & & & \\
\hline $\mathrm{HCO}_{3}^{-}$ & & & 1.00 & & & & & & \\
\hline $\mathrm{NO}_{3}^{-}$ & & & & 1.00 & & & & & \\
\hline $\mathrm{Na}^{+}$ & 0.96 & & & & 1.00 & & & & \\
\hline $\mathrm{Mg}^{+2}$ & 0.51 & 0.56 & -0.53 & & & 1.00 & & & \\
\hline $\mathrm{Ca}^{+2}$ & & 0.71 & & & & & 1.00 & & \\
\hline $\mathrm{K}^{+}$ & & -0.62 & & & & & -0.72 & 1.00 & \\
\hline $\mathrm{pH}$ & & & & & & & & & 1.00 \\
\hline
\end{tabular}

7 (UH7) es el acuífero más importante y se desarrolla sobre dolomías y calizas de Jurásico Medio. Dicha unidad presenta espesores de 100-250 m, una transmisividad entre $2.000-30.000 \mathrm{~m}^{2} /$ día, y se encuentra confinado en su mayor parte, excepto en el sector meridional de la cuenca. El muro de este acuífero se establece en un acuitardo de naturaleza margo - yesífera (UH9) en facies Keuper, a veces diapirizadas, que constituye siempre el basamento impermeable en el este de la cuenca. El acuífero UH4 es de escasa importancia por la superficie del mismo aflorante y está definido por los niveles detríticos del Cretácico Inferior, con transmisividades entre $1-50 \mathrm{~m}^{2} /$ día. El acuífero UH3 está definido por un conjunto de calizas y dolomías del Cretácico Superior con porosidad de conexión de poros y fracturas, con proceso de microkarstificación y dedolomitización. La unidad UH2 está 
situada en el centro de la cuenca, corresponde al Mioceno Medio (Ordóñez et al., 1975) con transmisividades entre $500-7000 \mathrm{~m}^{2} /$ día y está formado por calizas, con intercalaciones de margosas.

Las zonas de recarga de los diferentes acuíferos se encuentran fundamentalmente asociadas a los afloramientos de los acuíferos del Jurásico medio (UH7) y Cretácico superior (UH3) de la zona N, y aguas del Rio Júcar (aguas arriba de Villargordo del Júcar), a los cursos que se infiltran en la Llanura Manchega (ríos Jardín y Lezuza) y el entorno del canal de María Cristina. La descarga en régimen no perturbado, sin extracciones para regadío, se produce a lo largo del cauce del río Júcar desde al menos Valdeganga, hasta aguas debajo de Alcalá del Júcar (central Hidroeléctrica del Bosque).

En la fig. 3 se representan las aguas en el diagrama de Piper y se muestra una composición entre sulfatadas - cálcicas - magnésicas, y bicarbonatadas - cálcicas - magnésicas. Los índices de saturación (calculados a $25^{\circ} \mathrm{C}$ ) de la calcita, dolomita y yeso se recogen en la Tabla 3. El yeso se encuentra subsaturado, mientras que la calcita está ligeramente sobresaturada y la dolomita presenta valores de mayores de sobresaturación. Las correlaciones (lineales) entre los diferentes elementos se muestran en la Tabla 4. El comportamiento geoquímico de los elementos en las aguas del Júcar muestra dos agrupaciones importantes: el $\mathrm{Na}, \mathrm{Cl}$ y K (asociadas a en facies Keuper margo-yesíferas) y del $\mathrm{Mg}, \mathrm{Ca}$ y $\mathrm{SO}_{4}$ (procesos de dedolomitización en presencia de yeso).

\section{Consideraciones}

Existen diferencias importantes en la estructura, en el grado de confinamiento y en el tiempo de permanencia del agua en el sistema acuífero que alimenta ambas formaciones tobáceas (Ruidera y Valle del Jucar). El acuífero de Ruidera es de una sola capa, compartimentado y no confinado, mientras que el acuífero del Júcar en el sector Valdeganga - C.H. de El Bosque, es multicapa y parcialmente confinado. La descarga, en las lagunas de Ruidera, se produce en el contacto entre el acuífero y el acuitardo y en el caso del Río Júcar la descarga se produce por filtraciones a lo largo de un sector del valle. Sin embargo existen fuertes analogías, en cuanto a la capacidad las aguas de ambos acuíferos para formar depositar carbonatos tobáceos y, en particular, en la hidroquímica de sus aguas, ya que en ambos casos se trata de aguas carbonatadas - sulfatadas, más sulfatadas en el caso del Río Júcar, y en ambos casos de tipo cálcico - magnésico.

\section{Discusión}

\section{Comparación con los datos de otros de acuíferos actuales}

Para una interpretación de la hidroquímica de los acuíferos kársticos en áreas próximas a la Cuenca del Júcar y de la Cuenca Alta del Guadiana, se ha establecido su comparación con las aguas de los

\begin{tabular}{|c|c|c|c|c|c|c|c|c|c|c|c|c|c|}
\hline & $\begin{array}{c}\mathrm{Cl}^{-} \\
{[\mathrm{ppm}]}\end{array}$ & $\begin{array}{c}\mathrm{SO}_{4}^{2-} \\
{[\mathrm{ppm}]}\end{array}$ & $\begin{array}{l}\mathrm{HCO}_{3}^{-} \\
{[\mathrm{ppm}]}\end{array}$ & $\begin{array}{c}\mathrm{Na}^{+} \\
{[\mathrm{ppm}]}\end{array}$ & $\begin{array}{c}\mathrm{Mg}^{+2} \\
{[\mathrm{ppm}]}\end{array}$ & $\begin{array}{c}\mathrm{Ca}^{+2} \\
{[\mathrm{ppm}]}\end{array}$ & $\begin{array}{c}\mathrm{K}^{+} \\
{[\mathrm{ppm}]}\end{array}$ & $\mathrm{pH}$ & $\begin{array}{c}\sigma \\
{[\mu \mathrm{s} / \mathrm{cm}]}\end{array}$ & $I_{\text {calcita }}$ & $I_{\text {dolomita }}$ & $\mathrm{IS}_{\text {yeso }}$ & $\begin{array}{c}\log \\
\mathrm{pCO}_{2} \\
\end{array}$ \\
\hline \multicolumn{14}{|c|}{ Abril 1998} \\
\hline Min & 46.30 & 46.20 & 120.00 & 18.00 & 28.50 & 33.30 & 0.60 & 8.10 & 537.00 & 0.27 & 0.90 & -2.23 & -3.42 \\
\hline Max & 91.10 & 278.40 & 183.00 & 51.90 & 60.00 & 72.90 & 4.20 & 8.50 & 908.00 & 0.73 & 1.54 & -1.29 & -2.91 \\
\hline Media & 57.49 & 185.83 & 149.41 & 25.49 & 46.03 & 55.66 & 1.38 & 8.27 & 673.10 & 0.52 & 1.23 & -1.55 & -3.17 \\
\hline SD & 13.84 & 57.27 & 20.11 & 9.87 & 8.81 & 13.12 & 1.08 & 0.11 & 91.98 & 0.14 & 0.21 & 0.26 & 0.14 \\
\hline \multicolumn{14}{|c|}{ Diciembre 1998} \\
\hline Min & 30.80 & 30.40 & 200.00 & 20.20 & 18.50 & 32.10 & 1.20 & 7.40 & 465.00 & 0.04 & 0.08 & -2.38 & -3.08 \\
\hline Max & 83.50 & 239.10 & 300.50 & 50.60 & 60.20 & 89.20 & 4.60 & 8.30 & 1056.00 & 0.97 & 1.98 & -1.28 & -2.01 \\
\hline Media & 45.30 & 164.18 & 233.80 & 26.70 & 41.42 & 77.19 & 2.15 & 8.04 & 808.30 & 0.58 & 1.10 & -1.50 & -2.77 \\
\hline SD & 16.27 & 67.01 & 37.03 & 9.29 & 10.28 & 17.13 & 0.90 & 0.30 & 148.01 & 0.27 & 0.55 & 0.36 & 0.34 \\
\hline
\end{tabular}


Tabla 4.- Matriz de correlación lineal entre la concentración de los elementos mayores y el pH para aguas muestreadas en abril y diciembre de 1998 en el río Júcar

\begin{tabular}{|c|c|c|c|c|c|c|c|c|}
\hline & $\mathrm{Cl}^{-}$ & $\mathrm{SO}_{4}^{2-}$ & $\mathrm{HCO}_{3}^{-}$ & $\mathrm{Na}^{+}$ & $\mathrm{Mg}^{+2}$ & $\mathrm{Ca}^{+2}$ & $\mathrm{~K}^{+}$ & $\mathrm{pH}$ \\
\hline \multicolumn{9}{|c|}{ Abril 1998} \\
\hline $\mathrm{Cl}^{-}$ & 1.00 & & & & & & & \\
\hline $\mathrm{SO}_{4}^{2-}$ & & 1.00 & & & & & & \\
\hline $\mathrm{HCO}_{3}^{-}$ & & & 1.00 & & & & & \\
\hline $\mathrm{Na}^{+}$ & 0.93 & & & 1.00 & & & & \\
\hline $\mathrm{Mg}^{+2}$ & & 0.82 & & & 1.00 & & & \\
\hline $\mathrm{Ca}^{+2}$ & & 0.78 & & & & 1.00 & & \\
\hline $\mathrm{K}^{+}$ & 0.77 & 0.57 & & 0.91 & & 0.60 & 1.00 & \\
\hline $\mathrm{pH}$ & 0.53 & -0.57 & & & -0.74 & & & 1.00 \\
\hline \multicolumn{9}{|c|}{ Diciembre 1998} \\
\hline $\mathrm{Cl}^{-}$ & 1.00 & & & & & & & \\
\hline $\mathrm{SO}_{4}^{2-}$ & & 1.00 & & & & & & \\
\hline $\mathrm{HCO}_{3}^{-}$ & 0.79 & & 1.00 & & & & & \\
\hline $\mathrm{Na}^{+}$ & 0.75 & & & 1.00 & & & & \\
\hline $\mathrm{Mg}^{+2}$ & 0.72 & 0.77 & 0.52 & & 1.00 & & & \\
\hline $\mathrm{Ca}^{+2}$ & & 0.88 & & & 0.79 & 1.00 & & \\
\hline $\mathrm{K}^{+}$ & 0.85 & 0.55 & 0.59 & 0.78 & 0.81 & & 1.00 & \\
\hline $\mathrm{pH}$ & & & -0.50 & & & & & 1.00 \\
\hline
\end{tabular}

macizos carbonatados de la Sierra del Segura (Moral et al., 2008). Estos autores interpretan secuencialmente el quimismo de las numerosas surgencias de la Sierra del Segura. Los datos hidroquímicos permiten clasificar estas aguas como bicarbonatas cálcicas, los resultados se han reflejado en el diagrama de Piper, junto con los obtenidos en Ruidera y en el valle del Río Jucar (fig. 3). Únicamente se hacen ligeramente sulfatadas en fuentes profundas próximas al contacto con los sedimento evaporíticos del Trías.

Moral et al., (2008) hacen especial hincapié en la naturaleza de los materiales del acuífero y la cinética de las reacciones agua - roca. En este sentido, los autores exponen que se origina la disolución congruente de la calcita (reacción rápida) y la disolución de pequeñas cantidades de dolomita hasta alcanzar la saturación en calcita, todo ello produciendo la lenta disolución incongruente de la dolomita. La evolución teórica de la transferencia de masa modelizada con PHREEQC muestra cómo una vez se alcanza la saturación en calcita de las aguas comienza la lenta disolución incongruente de la dolomita, produciéndose la subsecuente reprecipitación de calcita. El resultado final de este proceso es el incremento en la concentración de bicarbonato y magnesio y un decrecimiento de la concentración de calcio. Los niveles de lignitos en las series juegan un papel importante en el aumento puntual de la $\mathrm{pCO}_{2}$ y el hecho que haya aguas fuertemente subsaturadas en calcita. Según estos autores, la disolución de yeso y/o anhidrita podría dar lugar a una intensificación del proceso de disolución incongruente de la dolomita, con la subsecuente precipitación de calcita.

Objeciones a los modelos basados en la recarga en suelos con altas $\mathrm{pCO}_{2}$ y su variación a lo largo del ciclo hidrogeológico

Como se expuso anteriormente, los modelos basados en la recarga en suelos con altas presiones parciales de $\mathrm{CO}_{2}, p \mathrm{CO}_{2}$, generadas por procesos microbiólogicos, explican muy bien y son coherentes para el sistema $\mathrm{H}_{2} \mathrm{O}-\mathrm{CaCO}_{3}-\mathrm{CO}_{2}$. Éstos permiten determinar la tasa de sedimentación de las 
tobas generadas en surgencias y a lo largo de valles (Ordóñez \& Felipe, 1988), así como la relación entre la morfología de los depósitos de tobas y los mecánicos de desgasificación y mecanismos biológicos y microbiológicos (Obst et al., 2009; Pedley, 2014). Por otra parte, estos modelos resultan especialmente atractivos para la interpretación de las formaciones tobáceas y espeleotemas en términos de registros paleoclimáticos y paleoambientales, basándose en la interpretación de las señales geoquímicas isotópicas $\left(\delta^{18} \mathrm{O}\right.$ y $\left.\delta^{13} \mathrm{C}\right)$ de los depósitos tobáceos y su datación mediante técnicas geocronológicas ${ }^{14} \mathrm{C}$ y U/Th y otras (Andrews, 2006).

Pero estos modelos basados en el sistema $\mathrm{H}_{2} \mathrm{O}$ $\mathrm{CaCO}_{3}-\mathrm{CO}_{2}$, a pesar de su fertilidad presentan una serie de limitaciones: i) no son adecuados para la modelización de la disolución incongruente de la dolomita y de la evolución de la porosidad en este tipo de reacción tan común en acuíferos dolomíticos; ii) no tienen en cuenta la cinética diferencial de disolución de los diferentes minerales presentes en acuíferos; iii) en los acuíferos comparados en esta revisión, y en los acuitardos que los definen, es común la presencia de yeso /anhidrita y sales solubles (cloruros y sulfatos) que pueden jugar un importante papel en el comportamiento hidroquímico de las aguas: y iv) no considera los procesos de mezclas de aguas de características químicas diferentes (salinidades, $\Sigma \mathrm{CO}_{2}$, temperatura, conductividad, TSD, etc.) y su influencia sobre el grado de saturación del sistema en calcita, en acuíferos compartimentados y parcialmente incomunicados, hecho especialmente importante durante etapas de disminución de las reservas hídricas en los mismos.

En el sentido de las limitaciones señaladas para el sistema $\mathrm{H}_{2} \mathrm{O}-\mathrm{CaCO}_{3}-\mathrm{CO}_{2}$, para explicar las aguas que dan lugar a los depósitos de tobas calcáreas y otros depósitos continentales (espeleotemas y calcretas), Brasier (2011) separa las aguas carbonatadas generadas por efecto de disolución de calcita en suelos con un horizonte húmico bien desarrollado con $\mathrm{pCO}_{2}$ altas (relacionadas con una importante cobertera vegetal en el área de infiltración) de las aguas susceptibles de precipitar carbonatos con una zona de infiltración donde esta cobertera vegetal está ausente, y con suelos de baja $\mathrm{pCO}_{2}$. En este caso, para alcanzar sobresaturación en calcita, Brasier (2011) recurre a mecanismos de desgasificación por enfriamiento y acción de los organismos fotosintéticos, perdida de $\mathrm{CO}_{2}$ de origen profundo, flujo turbulento en las aguas, así como el efecto de disolución de minerales con iones comunes con la calcita: yeso y dolomita.

En consecuencia, los procesos de génesis de tobas, tanto en su distribución geográfica de sus edificios y depósitos como sus tasas de sedimentación, son importantes las variaciones del $\mathrm{CO}_{2}$ a lo largo del ciclo hidrogeológico completo. Sin embargo, se pueden desarrollar manantiales y surgencias con aguas saturadas en calcita y, por lo tanto, susceptibles de formar depósitos tobáceos, bajo condiciones de desgasificación mecánica o biológica, recurriendo a modelos en los que no es necesaria la presencia en la zona de infiltración de suelos con altas presiones de $\mathrm{CO}_{2}$. La exposición y discusión de estos mecanismos que se revisan a continuación se ordena: a) la disolución incongruente de la dolomita (dedolomitización) y su análisis en términos de la sostenibilidad de la transmisividad del acuífero dolomítico; b) la cinética diferencial de las reacciones de disolución de los acuíferos carbonatados-sulfatados y la importancia de acuitardos dolomítico-yesíferos-margosos (facies Keuper), que constituyen el nivel parcialmente impermeable y origen de surgencias y filtraciones de algunos de los acuíferos más importantes; c) la importancia de las karstificaciones "sin" ácido carbónico de origen edáfico; d) la mezcla de aguas, procedentes de acuíferos multicapa (Modelo del Río Júcar), o acuíferos compartimentados en épocas de estiaje o sobreexplotación (Modelo de las Lagunas de Ruidera).

\section{La disolución incongruente de la dolomita}

En general, se asume (Corbellá et al., 2011) que las rocas dolomíticas se transforman en rocas calcáreas (dedolomitas) a temperaturas ambientales, con bajas presiones parciales de $\mathrm{CO}_{2}$, bajas concentraciones de $\mathrm{Mg}^{2+}$ y altas concentraciones de $\mathrm{Ca}^{2+}$ en aguas, de acuerdo con la reacción (no pseudomórfica):

$$
\mathrm{CaMg}\left(\mathrm{CO}_{3}\right)_{2}(\mathrm{dol})+\mathrm{Ca}^{2+} \leftrightarrow 2 \mathrm{CaCO}_{3}(\mathrm{cal})+\mathrm{Mg}^{2+}
$$

Las dedolomias son calizas procedentes de la dedolomitización de la dolomita y se presentan a menudo como formas pseudomorficas de los cristales de dolomita, que incluso mantienen núcleos de 
naturaleza dolomítica. Las aguas meteóricas pueden ser causa, entre otras, de la génesis de dedolomitas. La presencia de yeso/anhidrita puede favorecer el proceso de dedolomitización, aunque no es una condición necesaria (Eugercios, 2013).

El proceso de dedolomitización tiende a disminuir la porosidad de las rocas dolomíticas, lo cual bloquearía la transmisividad del acuífero (Ayora et al., 1998). La reacción (2) describe el reemplazamiento no pseudomórfico y presenta una variación de volumen molar de $\Delta \mathrm{v}^{0}=+9.50 \mathrm{~cm}^{3} / \mathrm{mol}$ (volumen molar de la calcita y dolomita son, respectivamente, 36.93 y $64.37 \mathrm{~cm}^{3} / \mathrm{mol}$, por lo que $\left.2 \cdot 36.9-64.4=9.50 \mathrm{~cm}^{3} / \mathrm{mol}\right)$. Este incremento de volumen molar llevaría consigo la necrosis parcial de la porosidad, que afecta a la permeabilidad y en consecuencia a la transmisividad del acuífero. Por ejemplo, la modelización de dicho proceso por Ayora et al., (1998), mediante el uso de un modelo de reacción de transporte multicomponente, indica que en 500 años apenas se podría alcanzar un pequeño borde de dedolomitización a lo largo de una fractura. Las observaciones petrográficas que estudiaron dichos autores muestran un reemplazamiento pseudomórfico (reacción (1), lo que mantiene constante la porosidad de la roca dolomítica. Los cálculos realizados mostraron que una roca dolomítica de $1 \mathrm{~m}$ de espesor podía ser dedolomitizada en un centenar de años, con unos parámetros razonables de flujo de agua subsaturada en calcita. Por otra parte el proceso conlleva una alcalinización del agua del acuífero, un incremento de la relación $\mathrm{Mg}^{2+} / \mathrm{Ca}^{2+}$.

Por lo tanto, las surgencias procedentes de algunos acuíferos dolomíticos que posteriormente forman parte de sistemas tobáceos han experimentado una disolución incongruente pseudomórfica de la dolomita (se mantiene constante la porosidad) o bien una disolución congruente (aumenta la porosidad), pero no en una dedolomitización no pseudomórfica (necrosis de porosidad). Esta es una condición básica en términos de parámetros de transporte reactivo y, por lo tanto, de sostenibilidad del proceso de dedolomitización. La disolución congruente, como comentaremos en el siguiente apartado, puede producir un agua rica en carbonato de calcio que contribuya a la formación de tobas.

\section{Cinética diferencial de disolución de las fases carbonatadas - sulfatadas presentes en los acuíferos dolomítico yesíferos}

Las fases más importantes que constituyen los acuíferos dolomítico yesíferos que se han analizado son calcita, dolomita y yeso, al menos en la zonas de infiltración. Nos centraremos en el yeso en detrimento de la anhidrita, al ser la fase mas abundante y estable en aguas poco salinas (menor actividad del agua) y/o a temperaturas menores de $42{ }^{\circ} \mathrm{C}$ (Hardie, 1967; Freyer \& Voigt, 2003). Por lo tanto, como primera aproximación en el modelo conceptual, se considera que en los acuíferos objeto de estudio la presencia de anhidrita es despreciable frente a la de yeso. La tasa de disolución de los minerales presentes en los acuíferos ha sido objeto de muchos estudios y modelizaciones. Emmanuelle \& Ague (2011) señalan que las tasas de disolución en medios naturales suelen ser de varios órdenes de magnitud inferiores a las medidas en laboratorio. Esta discrepancia se debe a diferentes procesos, destacando variabilidad del grado de saturación de la disolución; procesos de superficie que incluyen el tamaño de cristal, rugosidad de la superficie, desarrollo de fases que bloquean la disolución mineral y su naturaleza mono o policristalina, etc. En definitiva, las tasas de disolución están definidas tanto por parámetros ambientales (flujo y grado de saturación) como por las características de los minerales y se ven reflejadas en la discrepancia de resultados entre los estudios en laboratorio y en el medio natural.

La ecuación general de la tasa de disolución, R, se suele expresar con la siguiente ecuación:

$R=k_{S} \cdot\left(1-C / C_{s}\right)^{n}$

donde $k_{S}\left[\mathrm{mmol} \mathrm{cm}^{-2} \mathrm{~s}^{-1}\right]$ es la constante de velocidad de reacción; la relación entre la concentración de un elemento en disolución, $C$, y su solubilidad, $C_{S}$, es el grado de saturación, $C / C_{S}$; y $n$ es el orden de reacción que se obtiene experimentalmente, varía con la concentración de las disolución y presenta valores cercanos a 1 (exponente lineal) para concentraciones bajas (Lasaga, 1998).

Los valores de los parámetros cinéticos para las reacciones de disolución del yeso, calicita y dolomita varían de un estudio a otro, en función de las condiciones de experimentación. A modo orientativo, las 
tasas de disolución presentan los siguientes valores. El yeso presenta valores de $\mathrm{k}_{\mathrm{S}}=1.3 \cdot 10^{-7} \mathrm{~mol} \mathrm{~cm}^{-2} \mathrm{~s}^{-1}$, $n=1.2 \pm 0.2$ cuando $\mathrm{C} \leq 0.50 \cdot C_{\mathrm{S}}$ (Jeschke et al., 2001). Los valores de la constante de velocidad de disolución de la calcita y dolomita varían con el $\mathrm{pH}$ (Morse \& Arvidson, 2002). En el caso de la calcita, $\mathrm{k}_{\mathrm{S}}=5 \cdot 10^{-9} \mathrm{~mol} \mathrm{~cm}^{-2} \mathrm{~s}^{-1}(\mathrm{pH}=4)$ y k $\mathrm{S}_{\mathrm{S}}=10^{-10} \mathrm{~mol}$ $\mathrm{cm}^{-2} \mathrm{~s}^{-1}$ (para valores de $\mathrm{pH}$ superiores a 6 , donde es independiente del valor de $\mathrm{pH}$ ). La dolomita tiene un valor de $\mathrm{k}_{\mathrm{S}}$ muy dependiente del $\mathrm{pH}$ con valores de $10^{-10} \mathrm{~mol} / \mathrm{cm}^{2} \cdot \mathrm{s}(\mathrm{pH}=4), 3 \cdot 10^{-12} \mathrm{~mol} \mathrm{~cm}{ }^{-2} \mathrm{~s}^{-1}(\mathrm{pH}=7)$ y $5 \cdot 10^{-12} \mathrm{~mol} \mathrm{~cm}^{-2} \mathrm{~s}^{-1}$ (para valores de $\mathrm{pH}$ superiores a 9, donde $\mathrm{k}_{\mathrm{S}}$ es independiente del $\mathrm{pH}$ ).

Las reacciones que se producen en este tipo de acuíferos muestran una dependencia variable con la presión parcial de $\mathrm{CO}_{2}$, tanto en si mismas como por baja disponibilidad de $\mathrm{CO}_{2}$ en el medio (la hidrogeología puede condicionar que el acuífero se comporte como un sistema cerrado al $\mathrm{CO}_{2}$ ).

Es importante resaltar la dependencia la $\mathrm{pCO}_{2}$ con la variación de los valores de tasas de disolución de los distintos minerales, $\mathrm{R}^{\mathrm{i}}$ (donde $i$ es el mineral). Esto permitiría plantear el siguiente modelo conceptual de la tasas de disolución en un acuífero desarrollado sucesivamente y/o simultáneamente sobre yeso - calcita - dolomita como:

$$
\begin{aligned}
& R_{\text {congruente }}^{\text {yes }}\left(\text { independiente de la } p \mathrm{CO}_{2}\right) \gg \gg R^{\text {tecalcita }}\left(\text { dependiente de la } \mathrm{pCO} \mathrm{CO}_{2}\right) \\
& >R_{\text {congruente }}^{\text {dolomita }}\left(\text { dependiente de la } p \mathrm{CO}_{2}\right)
\end{aligned}
$$

La carbonatación de sulfatos evaporíticos es un proceso diagenético especialmente interesante tanto por la extensión que puede alcanzar como por las implicaciones que tiene.

Se considera que este proceso ha conducido a la formación de volúmenes importantes de calizas diagenéticas a partir de yesos en numerosos afloramientos. Experimentalmente, Fernández-Díaz et al., (2008) obtienen calcita a partir de la disolución del yeso una vez que se supera la saturación en este mineral. Por lo tanto se puede escribir que:

$$
\begin{aligned}
& R_{\text {congruente }}^{\text {yeso }}\left(\text { independiente de la } \mathrm{pCO}_{2}\right)> \\
& \quad>R_{\text {calcitizatión incongruente }}^{\text {yeso }}\left(\text { dependiente de la } \mathrm{pCO}_{2}\right)
\end{aligned}
$$

Por último, la disolución incongruente de la dolomita (dedolomitización) es siempre posterior a la disolución congruente de la dolomita, y comienza cuando se alcanza la saturación en calcita. Sin embargo, si coexiste en el acuífero con la calcita podría producirse una nucleación heterogénea de calcita y el proceso de dedolomitización adelantarse:

$$
\begin{aligned}
& R_{\text {calcitizatión incongruente }}^{\text {dolonindependiente de la } \mathrm{pCO}}\left(\mathrm{CO}_{2}\right) \\
& \cong(\text { en presenia decalcita }) R_{\text {congruente }}^{\text {dolomita }}\left(\text { dependiente de la } \mathrm{pCO}_{2}\right)
\end{aligned}
$$

La cinética de la disolución de las fase consideradas puede jugar un importante papel en la modelización de la hidroquímica de las aguas. Como conclusión, la $\mathrm{pCO}_{2}$ puede tener poca importancia en la cinética de disolución, salvo en el caso de la calizas puras. Además, la presencia de yeso adquiere una gran importancia en este tipo de acuíferos y acuitardos con yeso-calcita-dolomita y las dolomías suprayacentes, como lo que estamos analizando en el caso de Ruidera y del valle del Río Jucar (sector Valdeganga - C. H. del Bosque). Todo ello modifica sustancialmente las tendencias hidroquímicas y se refleja tanto en modelos experimentales, como en la observación petrográfica de génesis de calizas de dedolomitización, y en la calcitización de yesos.

\section{Importancia de las karstificaciones sin ácido carbónico de origen edáfico en acuíferos con presencia conjunta de minerales sulfatados cálcicos y dolomita}

El efecto del ión común en la dedolomitización ha sido abordado por Bischoff et al. (1994), proponiendo una elegante solución a la disolución de carbonatos sin variación de la $p \mathrm{CO}_{2}$, donde están involucradas reacciones de dedolomitización en presencia de yesos. Dicho estudio se centra en el acuífero que alimenta el Lago de Bañolas (Gerona). La karstificación del acuífero tiene lugar a lo largo de la superficie de contacto entre una formación yesífera (F. Beuda) y una formación dolomítica (F. Parafita). Este proceso se ha reconocido aquí por primera vez y es muy significativo para desarrollar una karstificación a gran escala, sin presencia de $\mathrm{CO}_{2}$ generado en el suelo de la zona de infiltración. La dedolomitización inducida por el yeso puede ser la causa de la génesis de otros muchos sistemas kársticos atribuidos a la acción de aguas carbónicas con $\mathrm{CO}_{2}$ de origen edáfico.

El modelo de reacción de balance de masas se construye teniendo en cuenta la hidroquímica del 
agua de Bañolas, estableciendo el proceso de dedolomitización de acuerdo con la reacción:

$x \mathrm{MgCa}\left(\mathrm{CO}_{3}\right)_{2}+x \mathrm{CaSO}_{4} \cdot 2 \mathrm{H}_{2} \mathrm{O}=2 x \mathrm{CaCO}_{3}$ $+x \mathrm{Mg}^{+2}+x \mathrm{SO}_{4}^{-2}+2 x \mathrm{H}_{2} \mathrm{O}$.

Según los autores, el agua de Bañolas esta subsaturada con respecto al yeso. Sin embargo el contenido en sulfatos excede el ion magnesio, por lo que plantea la ecuación de disolución del yeso:

$y \mathrm{CaSO}_{4} \cdot 2 \mathrm{H}_{2} \mathrm{O}=y \mathrm{Ca}^{+2}+y \mathrm{SO}_{4}^{-2}+2 y \mathrm{H}_{2} \mathrm{O}$.

Como la $\mathrm{pCO}_{2}$ en el lago excede a la atmosférica, la interacción con calcita puede dar exceso de carbonatos, lo que justifica el aumento de bicarbonatos en el sistema:

$z \mathrm{H}_{2} \mathrm{CO}_{3}+z \mathrm{CaCO}_{3}=z \mathrm{Ca}^{+2}+2 z \mathrm{HCO}_{3}^{-}$.

La combinación de las tres ecuaciones nos permite escribir:

$z \mathrm{H}_{2} \mathrm{CO}_{3}+x \mathrm{MgCa}\left(\mathrm{CO}_{3}\right)_{2}+(x+y) \mathrm{CaSO}_{4} \cdot 2 \mathrm{H}_{2} \mathrm{O}$

$=(2 x-z) \mathrm{CaCO}_{3}+x \mathrm{Mg}^{+2}+(y+z) \mathrm{Ca}^{+2}$

$+(\mathrm{x}+\mathrm{y}) \mathrm{SO}_{4}^{-2}+2 z \mathrm{HCO}_{3}^{-}+2(x+\mathrm{y}) \mathrm{H}_{2} \mathrm{O}$.

El análisis de la variación de volumen molar de la reacción es siempre negativa independiente de los coeficientes de ajuste. Si el volumen molar de dolomita, calcita y yeso son respectivamente $64.35,36.94$ y 74.31 $\mathrm{cm}^{3} / \mathrm{mol}$ (Berner, 1971), la variación del volumen molar de la reacción es $(2 \mathrm{x}-\mathrm{z}) \cdot 36.94-\mathrm{x} \cdot 64.35-(\mathrm{x}+\mathrm{y})$. $74.31=-36.94 \cdot x-74.31 \cdot y-36.94 \cdot z$. Como los valores de $\mathrm{x}, \mathrm{y}, \mathrm{z}$ son siempre positivos y mayores que 0 , la igualdad anterior es siempre negativa, lo que implica que la reacción de disolución de la dolomita propuesta genere porosidad y, por lo tanto, favorezca la transmisividad y la sostenibilidad temporal de la reacción propuesta. Además, en dicha reacción no interviene el $\mathrm{CO}_{2}$ y explica la génesis de facies de carniolas (dedolomita) y la calcitización de los yesos (ambos procesos identificados petrográficamente en el acuífero).

La ecuación permite además hacer una comparación entre los datos de la hidroquímica de las aguas de tal modo que $\left[\mathrm{Mg}^{+2}\right]=\mathrm{x} ;\left[\mathrm{HCO}_{3}^{-}\right]=2 \mathrm{z}$; $\left[\mathrm{SO}_{4}^{-2}\right]=(\mathrm{x}+\mathrm{y}) ;\left[\mathrm{Ca}^{+2}\right]=(\mathrm{y}+\mathrm{z})$. Las propuestas permiten señalar que la karstificación puede avanzar sin que sea necesario el aporte de $\mathrm{CO}_{2}$ del suelo. Los autores de este modelo señalan el importante papel en el incremento del $\mathrm{CO}_{2}$ en el medio, por la oxidación de la materia orgánica dispersa en las rocas.

Por último, este modelo está de acuerdo con el efecto de ion común de Brasier (2011) y la reacción de la llamada impropiamente reacción de dedolomitización (reacción (1), por Eugercios (2013) para la interpretación de la parte alta de las Lagunas de Ruidera. Este modelo podría extenderse al área de recarga de los acuíferos, tanto porque no es necesario la presencia de un suelo vegetal impropio de áreas áridas, como por el hecho de que las fábricas de las facies carniolas de los materiales superiores del Keuper, presentan texturas y fábricas petrográficas coherentes con las reacciones propuestas para explicar la hidroquímica. Los altos contenidos en sulfatos se asocian a la disolución del yeso y, junto a los cloruros, a las sales solubles presentes en las facies Keuper.

\section{Mezcla de aguas en surgencias de acuíferos multicapa o compartimentados temporalmente o ocasionalmente}

Otro proceso geoquímico que puede llegar a ser clave en aguas procedentes de acuíferos multicapa (Modelo Valle del Júcar) o acuíferos compartimentados en épocas de estiaje o sobreexplotación (Modelo de Ruidera) es la mezcla de aguas.

En dichos acuíferos, tanto unicapa y multicapa como compartimentados y que pueden llegar a desconectarse en momentos de baja del acuífero, la mezcla de aguas con distintas características fisicoquímicas puede generar aguas saturadas en calcita, que posteriormente contribuyan a la formación de sistemas tobáceos.

La solubilidad de la calcita depende de varios factores: temperatura (que tiene incidencia en la constante de equilibrio), salinidad (en los coeficientes de actividad iónicos) y la $\mathrm{pCO}_{2}(\mathrm{o} \mathrm{pH})$. Esto hace que la solubilidad de dicho carbonato no sea lineal con cualquiera de las variables independientemente, adquiriendo una expresión cúbica. Por ello, la mezcla de dos aguas con distintos estados de saturación puede producir un agua de mezcla sobresaturada o subsaturada en función de dichas características fisicoquímicas y la proporción de mezcla. Ejemplos comunes son el desarrollo de sistemas kársticos de acuíferos calcíticos en la zona de mezcla (subsaturada en calcita) de aguas marinas y aguas del acuífero (ambas saturas en calcita) (Wigley \& Plummer, 
1976; Sanz et al., 2011). Por otro lado, la mezcla de dos fluidos con diferente salinidad también se ha usado para explicar la disolución de carbonatos en profundidad y la formación de depósitos minerales hidrotermales (Corbella et al., 2011).

El efecto de la salinidad (también llamado efecto de la fuerza iónica) se produce cuando dos soluciones con diferente salinidad se mezclan entre sí. La solución resultante está subsaturada en calcita como resultado de la dependencia no lineal de los coeficientes de actividad, que hace que los coeficientes de actividad decrezcan a medida que aumenta la salinidad. La saturación de una mezcla también depende del $\mathrm{pH}$ y $\mathrm{pCO}_{2}$ debido a la fuerte dependencia de las especies de carbonato con el $\mathrm{pH}$. Finalmente, las variaciones de temperatura pueden también afectar a la saturación de una mezcla, debido a la dependencia no lineal de las constantes de equilibrio de minerales con la temperatura.

\section{Conclusiones-consideraciones finales}

La formación de sistemas tobáceos de aguas procedentes de acuíferos calizos está estrechamente relacionada con el estado de saturación de la calcita, dependiente de la fuerza iónica, la presión parcial de $\mathrm{CO}_{2}$ y temperatura. Así, la precipitación de calcita exige índices de saturación superiores a +0.5 y su disolución requiere índice saturación inferiores a -0.3 (White, 1997). La $\mathrm{pCO}_{2}$ está condicionada por la velocidad de infiltración y su grado de conexión con el exterior y por el contenido de $\mathrm{CO}_{2}$ del suelo. El papel del $\mathrm{CO}_{2}$, por lo tanto, va a depender del tipo de acuífero, fracturado y/o poros conectados, del clima y del los tipos de suelos desarrollados. La perdida de $\mathrm{CO}_{2}$ en la surgencia por reequilibrio con la presión atmosférica, el calentamiento del agua, los mecanismos biológicos fotosintéticos y la evaporación del agua puede conducir al aumento del índice de saturación en calcita y por lo tanto a la formación de sistemas tobáceos.

Las aguas generadas en acuíferos calizos, en este contexto, son bicarbonatadas cálcicas, según la nomenclatura de Piper (fig. 3). Las aguas de la Sierra del Segura, tomadas como referencia en este trabajo, presentan un carácter bicarbonatado cálcico, acorde con la naturaleza calcítica y moderadamente magnésica de los diferentes acuíferos del sistema.
Sin embargo, las aguas de los acuíferos que se estudian en este trabajo, Lagunas de Ruidera, y Río Júcar (Valdeganga - C.H. de El Bosque), son bicarbonatadas-sulfatadas cálcicas-magnésicas, con un contenido apreciable en cloruros-sódicos.

Las aguas de los acuíferos de las Lagunas de Ruidera y del Río Júcar evolucionan en un acuífero de naturaleza calcítico-dolomítico, con un acuitardo que es de naturaleza arcilloso - yesífera, con presencia de cloruros. Aunque el acuífero mas importante del valle del Jucar coincide en características litológicas con el de las Lagunas de Ruidera, existen otros acuíferos que forman parte del sistema acuífero que descarga en el valle del Jucar, que presentan dolomías (Cretácico Superior) y otros niveles de dolomías, como la Tierra Blanca de La Roda (García del Cura et al., 2001), y de yesos, como la formación Yesares, ambos del Terciario Superior de la Cuenca del Júcar. Todos ellos en menor escala contribuyen a la hidroquímica de las aguas del Rio Júcar y a la génesis de los depósitos tobáceos que se han depositado en la zona anteriormente mencionada.

Otro aspecto importante a considerar son los valores de $\mathrm{pCO}_{2}$ en la zona de recarga. Ambos acuíferos están situados en un clima templado mediterráneo de matiz continental, con precipitaciones medias inferiores a $360 \mathrm{~mm}$ y temperaturas medias de $13.5^{\circ} \mathrm{C}$. El tipo de suelos que se desarrollan son litosuelos, con un fuerte desarrollo de calcretas y con un horizonte húmico débilmente desarrollado, en el que no es fácil suponer la presencia de $\mathrm{pCO}_{2}$ elevadas.

En este trabajo hemos realizado consideraciones sobre las diferentes reacciones agua - roca que condicionan la hidrogeoquímica de las aguas que generan sistemas tobáceos y que pueden tener lugar en los acuíferos y/o acuitardos. Podemos destacar los siguientes procesos geoquímicos:

- La reacción de disolución/precipitación de calcita es la más conocida y utilizada y es la que suele considerar tanto a los procesos de disolución asociada a los procesos de karstificación y los consiguientes depósitos de espeleotemas como a la formación de tobas calcáreas.

- La tasa de disolución de la dolomita es de varios ordenes de magnitud menor que la de la calcita, para valores comparables del índice de saturación. 
- Las reacciones de dedolomitización son independientes de la actividad de los iones carbonatados/bicarbonatados del agua de infiltración y la condición límite para que la reacción sea sostenible es que dicha reacción sea de reemplazamiento pseudomórfico; en este contexto no se producirá la necrosis de la porosidad y la infiltración del agua puede continuar. Su desarrollo se encuentra modulado también por la cinética del crecimiento de la calcita, por lo que se puede concluir que es un proceso muy lento.

- La presencia de yesos activa extraordinariamente el proceso de dedolomitización. El efecto de kastificación se produce sin presencia de ácido carbónico y generando aguas fuertemente saturadas en calcita.

- La presencia de yesos activa extraordinariamente el proceso de dedolomitización, pudiendo señalarse el efecto de kastificación sin necesidad de adición de ácido carbónico y generando aguas fuertemente saturadas en calcita.

- La solubilidad y la tasa de disolución del yeso y/o anhidrita es de varios órdenes de magnitud superior a la de calcita y dolomita, para valores comparables de los índices de saturación. Este hecho mejora la eficiencia del proceso de dedolomitización. El factor limitante del proceso de disolución del yeso es que se alcance en la solución la saturación en calcita, proceso bastante común que se describe petrográficamente como calcitización de yesos.

- La mezcla de aguas puede jugar un papel importante ya sea de un acuífero ocasionalmente compartimentado o de un acuífero multicapa. En este contexto, el carácter no lineal de la mezcla de aguas condiciona las aguas de los manantiales y filtraciones que tengan una alta productividad de tobas.

Por lo tanto las aguas de un acuífero cuando manan o se filtran y afloran a la superficie topográfica, pueden alcanzar su saturación en calcita y, por lo tanto, precipitar tobas de aguas dulces por muchos mecanismos, sin que sea necesario recurrir al modelo, por otra parte muy fértil, de tener suelos de alta $\mathrm{pCO}_{2}$. La modelización hidroquímica de los acuíferos de naturaleza dolomítico y dolomítico - yesífera, por otra parte muy comunes en la geología de la península Ibérica, pueden explicar en parte los abundantes depósitos tobáceos actuales y fósiles.

\section{AGRADECIMIENTOS}

Este trabajo se ha realizado en el marco del proyecto CGL201125162 del Ministerio de Economía y Competitividad. Nos gustaría mostrar un especial agradecimiento a J.A. Gónzalez, M. Pedley y M. A. García del Cura, con los cuales hemos compartido muchas horas de campo y discusión sobre las tobas calcáreas.

\section{Referencias}

Andrews, J.E. (2006). Palaeoclimatic records from stable isotopes in riverine tufas. Earth-Science Reviews: 75: 85-104. http://dx.doi.org/10.1016/j. earscirev.2005.08.002.

Ayora, C.; Taberner, C.; Saaltink, M.W. \& Carrera, J. (1998). The genesis of dedolomites: a discusion based on reactive transport modelling. Journal of Hydrology, 209: 346-365. http://dx.doi.org/10.1016/ S0022-1694(98)00095-X.

Banks, V.J. \& Jones, P.F. (2012). Hydrogeological Significance of Secondary Terrestrial Carbonate Deposition in Karst Environments. In: Hydrogeology - A Global Perspective (Kazemi, G.A., Ed.), InTech., 43-78. http://dx.doi.org/10.5772/29300.

Berner, R.A. (1971). Principles of chemical sedimentology. McGraw-Hill, 240 pp.

Bischoff, J.L.; Juliá, R.; Shanks III, W.C. \& Rosenbauer, R.J. (1994). Karstification without carbonic acid: Bedrock dissolution by gypsum-driven. Geology, 22: 995-998. http://dx.doi.org/10.1130/0091-7613 (1994)022<0995:KWCABD>2.3.CO;2.

Brasier, A.T. (2011). Searching for travertines, calcretes and speleothems in deep time: Processes, appearances, predictions and the impact of plants. EarthScience Reviews, 104: 213-239. http://dx.doi.org/ 10.1016/j.earscirev.2010.10.007.

Capezzuoli, E.; Gandin, A. \& Pedley, M. (2013). Decoding tufa and travertine (fresh water carbonates) in the sedimentary record: The state of the art. Sedimentology, 61: 1-21. http://dx.doi.org/10.1111/sed. 12075.

Corbellá, M.; Escorcia, L.C. \& Gomez-Rivas, E (2011). Impact of Dedolomitization on Reservoir Quality: Insights from Reactive Transport Simulations. Macla, 15: 65-66.

Emmanuel, S. \& Ague, J. (2011). Impact of nano-size weathering products on the dissolution rates of primary minerals. Chemical Geology, 282: 11-18. http://dx.doi.org/10.1016/j.chemgeo.2011.01.002.

Eugercios, A. (2013). Interacciones acuífero-lago y biogeoquímica del nitrógeno en ambientes kársticas. 
Tesis Doctoral, Universidad Complutense de Madrid, $414 \mathrm{pp}$.

Fernández-Díaz, L.; Rodríguez - Blanco, J.D. \& Prieto Rubio, M. (2008). Interacción entre cristales de yeso y soluciones carbonatadas: cinética y transformaciones. Macla, 9: 93-94.

Fernández-Fernández, A. (1996). Geomorfología del cañón del río Júcar en la comarca de La Manchuela (Albacete). Tesis Doctoral. Universidad Complutense de Madrid, $721 \mathrm{pp}$.

Fernández-Fernández, A.; García del Cura, M.A.; González Martín, J.A. \& Ordóñez, S. (2000). Morfogénesis y sedimentación carbonática Pleistocena en el valle del Júcar (Albacete). Geotemas, 1: 353-357.

Fernández-Fernández, A.; González Martín, J.A.; García del Cura, M.A. \& Ordóñez, S. (1997). Los edificios tobáceos Holocenos en el valle del Júcar en la Manchuela (Albacetete, España). Études de Géographie Physique, 26: 61-62.

Fernández-Fernández, A.; González Martín, J.A.; García del Cura, M.A., Benavente, D. \& Ordóñez, S. (1999). Aproximación químico-física a la precipitación de carbonatos en cauces fluviales: río Júcar (España). Actas II Congreso Ibérico de Geoquímica, Lisboa. 1: 222-226.

Freyer, D. \& Voigt, W. (2003). Crystallization and phase stability of $\mathrm{CaSO}_{4}$ and $\mathrm{CaSO}_{4}$ - based salts. Monatshefte für Chemie, 134: 693-719. http://dx. doi.org/10.1007/s00706-003-0590-3.

García del Cura, M.A.; Calvo, J.P.; Ordóñez, S.; Jones, B. \& Cañaveras, J.C. (2001). La Roda "white earth" (Pliocene, central Spain): Petrographic and geochemical evidence for the formation of primary, bacterially induced lacustrine dolomite. Sedimentology. 48: 897-915. http://dx.doi.org/10.1046/j.1365-3091. 2001.00388.x.

Garrels, R.M \& Mackenzie, F.T. (1967). Origin of the chemical composition of springs and lakes. In: Equilibrium concepts in natural water systems: American Chemical Society, Advances in Chemistry Series, 67: 222-242.

Glynn, P.D. \& Plummer, L.N. (2005). Geochemistry and the understanding of groundwater systems. Hydrogeology Journal, 13: 263-287. http://dx.doi. org/10.1007/s 10040-004-0429-y.

Grande, F.; Ordóñez, S.; González Martín, J.A. \& García del Cura, M.A. (1997). La recuperación hídrica de las Lagunas de Ruidera y su repercusión sobre las barreras tobáceas. Études de Géographie Physique, 26: $157-158$.

Hardie, L.A. (1967). The gypsum-anhydrite equilibrium at one atmosphere pressure. The American Mineralogist, 52: 171-200.

Jeschke, A.; Vosbeck, K. \& Dreybrodt, W. (2001). Surface controlled dissolution rates of gypsum in aqueous solutions exhibit nonlinear dissolution kinetics.
Geochimica et Cosmochimica Acta, 65: 27-34 http://dx.doi.org/10.1016/S0016-7037(00)00510-X.

Lasaga A.C. (1998). Kinetic Theory in the Earth Sciences. Princeton Ser. in Geochemistry, Princeton University Press, Princeton. 811 pp.

Montero, E. (1994). Funcionamiento hidrogeológico del sistema de las lagunas de Ruidera. Tesis Doctoral, Universidad Complutense de Madrid.

Moral, F.; Cruz-Sanjulián, J.J. \& Olías, M. (2008). Geochemical evolution of groundwater in the carbonate aquifers of Sierra de Segura (Betic Cordillera, southern Spain). Journal of Hydrology, 360: 281-296. http://dx.doi.org/10.1016/j.jhydrol.2008.07.012.

Morse, J.W. \& Arvidson, R.S. (2002). The dissolution kinetics of major sedimentary carbonate minerals. Earth-Science Reviews, 58: 51-84. http://dx.doi. org/10.1016/S0012-8252(01)00083-6.

Niñerola, S. \& Torrens, J. (1979). Características hidrogeológicas generales de la Cuenca Alta del Rio Guadiana. Hidrogeología y Recursos Hidraúlicos, 4: 309-326.

Obst, M.; Dynes, J.J.; Lawrence, J.R.; Swerhone, G.D.W.; Benzerara, K.; Karunakaran, C.; Kaznatcheev, K.; Tyliszczak, T. \& Hitchcock, A.P. (2009). Precipitation of amorphous $\mathrm{CaCO}_{3}$ (aragonite-like) by cyanobacteria: A STXM study of the influence of EPS on the nucleation process. Geochimica et Cosmochimica Acta, 73: 4180-4198. http://dx.doi.org/10.1016/j.gca. 2009.04.013.

Ordóñez, S. \& Felipe, A. (1988). Modelización matemática de la hidroquímica de las aguas de un macizo dolomítico - yesífero. Aplicación a la génesis de los travertinos de las Lagunas de Ruidera. Estudios Geológicos, 44: 99-105.

Ordóñez, S. \& García del Cura, M.A. (1982). Recent and Tertiary fluvial carbonates in Central Spain. In: Modern and Ancient Fluvial Systems (Collinson, J.D. \& Lewin, J. Eds.). International Association of Sedimentologist Special Publication, 6, 485-497. doi: http://dx.doi.org/10.1002/9781444303773.ch39.

Ordóñez, S.; García del Cura, M.A. \& Carballal, R. (1978). Stromatolites and oncolites in the modern fluvial environment. 10th International Congress on Sedimentology, Jerusalem. Abstracts, 2: 489-490.

Ordóñez, S.; González, J. A.; García del Cura, M.A. \& Pedley, H.M. (2005). Temperate and semi-arid tufas in the Pleistocene to Recent fluvial barrage system in the Mediterranean area: The Ruidera Lakes Natural Park (Central Spain). Geomorphology, 69: 332-350. http://dx.doi.org/10.1016/j.geomorph.2005.02.002.

Ordóñez, S.; Santos, J.A. \& García del Cura, M.A. (1975). Contribución al conocimiento de la evolución de la cuenca del río Júcar durante el Neógeno - Cuaternario. Congreso Iberoamericano de Geología Económica. Buenos Aires. 3: 579-596.

Parkhurst, D.L. \& Appelo, C.A.J. (1999). User's guide to PHREEQC (version 2) — a computer program for 
speciation, batch-reaction, one-dimensional transport, and inverse geochemical calculations. U.S. Geological Survey Water-Resources Investigations Report 99-4259, 312 pp.

Pedley, M. (2014). The morphology and function of thrombolitic calcite precipitating biofilms: A universal model derived from freshwater mesocosm experiments. Sedimentology, 61: 22-40. http://dx.doi. org/10.1111/sed.12042.

Pedley, M., Rogerson, M. \& Middleton, R. (2009). Freshwater calcite precipitates from in vitro mesocosm flume experiments: a case for biomediation of tufas. Sedimentology, 56: 511-527. http://dx.doi.org/10. 1111/j.1365-3091.2008.00983.x.

Pentecost, A. \& Viles, H.A. (1994). A review and reassessment of travertine classification. Géographie physique et Quaternaire, 48: 305-314.

Pentecost, A. (2005). Travertine. Springer-Verlag, Berlin and Heidelberg. 445 pp.

Plata, A. \& Pérez-Zabaleta, E. (1995). Estudio de la hidrología isotópica de la Cuenca del Guadiana. CEDEX Documento Interno. 224 pp.

Rogerson, M.; Pedley, H.M.; Wadhawan, J.D. \& Middleton, R. (2008). New insights into biological influence on the geochemistry of freshwater carbonate deposits. Geochimica et Cosmochimica Acta, 72: 4976-4987. http://dx.doi.org/10.1016/j.gca.2008.06.030.

Sanz, D. (2005). Contribución a la caracterización geométrica de las unidades hidrogeológicas que integran el sistema de acuíferos de la Mancha Oriental. Tesis Doctoral, Universidad Complutense de Madrid, $251 \mathrm{pp}$.

Sanz, D.; Martínez-Alfaro, P.E.; Castaño, C. \& GómezAlday, J.J. (2005). Caracterización de los dominios hidrogeológicos individualizados en el Sistema Mancha Oriental. SE Español. Geogaceta, 38: 251-254.

Sanz, E.; Ayora, C. \& Carrera, J. (2011). Calcite dissolution by mixing waters: geochemical modeling and flow-through experiments. Geologica Acta, 9: 67-77.

Souza-Egipsy, V.; García del Cura, M.A.; Ascaso, C.; de los Ríos, A.; Wierzchos, J. \& González-Martín, J.A. (2006). Interaction between Calcite and Phosphorus in Biomineralization Processes in Tufa Carbonates. International Review of Hydrobiology, 91: 222-241. http://dx.doi.org/10.1002/iroh.200510845.

Thrailkill, J. (1968). Chemical and hydrologic factors in the excavation of limestone caves. Geological Society of America Bulletin, 79: 1637-1658. doi: http://dx. doi.org/10.1130/0016-7606(1968)79[19:CAHFIT] 2.0.CO;2.

White, W.B. (1997). Thermodynamic equilibrium, kinetics, activation barriers, and reaction mechanisms for chemical reactions in Karst Terrains. Environmental Geology, 30: 46-58. http://dx.doi.org/10.1007/ s002540050131.

Wigley, T.M.L.\&Plummer,L.N.(1976). Mixing of carbonate waters: Geochimica et Cosmochimica Acta, 40: 989995. http://dx.doi.org/10.1016/0016-7037(76)90041-7. 